\title{
ALTERAÇÕES MORFO-ANATÔMICAS DAS FOLHAS DE MILHO SUBMETIDAS À APLICAÇÃO DE NICOSULFURON ${ }^{1}$
}

\author{
FABÍOLA V. MÔRO ${ }^{2}$ e CARLOS F. DAMIÃO FILHO ${ }^{3}$
}

\section{RESUMO}

O objetivo desse trabalho é descrever os sinais externos de intoxicação e as alterações histológicas nas folhas de híbridos de milho submetidos à aplicação de nicosulfuron. Verificou-se que os híbridos tratados apresentaram descoloração da parte basal das lâminas das folhas centrais, enrugamento e enrolamento das extremidades do limbo foliar, aos 7 dias após a aplicação do produto. As alterações anatômicas observadas restringiramse às células componentes do sistema dérmico.

Palavras chave: Sulfoniluréias, herbicida pós-emergência, Zea mays, injúria.

\section{ABSTRACT \\ Morphological and anatomical alterations in corn leaves submitted to nicosulfuron}

This work aimed to describe the injury symptoms and histological modifications in the leaf blade of corn hybrids submitted to nicosulfuron. Seven days after the herbicide application, injury symptoms were expressed as

\section{INTRODUÇÃO}

A aplicação de herbicidas geralmente possibilita um acréscimo na produção de uma cultura, devido à eliminação da competição de plantas daninhas por água e nutrientes. Ainda que um herbicida possa ser prejudicial à cultura, a produção pode ser aumentada devido ao controle das plantas invasoras.

Diversos pesquisadores tem investigado a tolerância das culturas aos herbicidas, uma vez que tem sido relatados efeitos variados $\mathrm{e}$ indesejáveis dos herbicidas sobre a própria cultura.

Efeitos fisiológicos e citológicos em plântulas de milho, 4 dias após o tratamento com chlorosis and wrinkledness of leaf blade. The anatomical changes were restricted to the epidermal cells.

Key words: Sulfonyllureia, postemergence, Zea mays, herbicide injury.

BAS $9052 \mathrm{OH}$, foram observados por Asareboamah \& Fletcher (1983). Houve inibição de crescimento das plântulas e o aparecimento de folhas com cor púrpura em doses maiores que $0,04 \mathrm{~kg} / \mathrm{ha}$, causada provavelmente pelo acúmulo de antocianinas e o decréscimo dos níveis de clorofila. Em doses muito baixas $(0,02$ e $0,04 \mathrm{~kg} / \mathrm{ha})$, a segunda e terceira folhas recentemente expandidas, mostraram-se cloróticas.

Kleppe \& Harvey (1989), verificaram que a aplicação de Sethoxydim em jato dirigido em pós-emergência, ocasionou injúrias em plantas de milho. Os sintomas foram caracterizados por acamamento, manchas cloróticas e necrose das folhas expandidas. $\mathrm{O}$ vigor e a produção foram levemente, mas significativamente, reduzidos.

\footnotetext{
${ }^{1}$ Recebido para publicação em 13/07/98 e na forma revisada em 17/02/99.

${ }^{2}$ Dept $^{\circ}$ de Biologia Aplicada à Agrop., FCAV/UNESP, Rod. Carlos Tonanni, km 5, CEP: 14870-000, Jaboticabal/SP.

${ }^{3}$ Dept $^{\circ}$ de Biologia Aplicada à Agrop., FCAV/UNESP, Rod. Carlos Tonanni, km 5, CEP: 14870 -000, Jaboticabal/SP.
} 
Em experimentos para controlar Panicum miliaceum em milho doce, o Sethoxydim aplicado em pós-emergência em jato dirigido, ocasionou severas injúrias nas doses de 57, 114 e $227 \mathrm{~g} / \mathrm{ha}$, reduzindo o vigor das plantas e o "stand" (Kleppe \& Harvey,1991).

A aplicação de nicosulfuron em pós emergência nas doses de 18 a $140 \mathrm{~g}$ de ingrediente ativo por hectare, em oito híbridos de milho doce, ocasionou redução no vigor e sinais de injúria crescentes com o aumento da dose de nicosulfuron (Morton \& Harvey, 1992).

Sintomas de injúria em cultivares de milho doce em resposta à aplicação de nicosulfuron e primisulfuron em pós-emergência, nas doses de $35 \mathrm{~g} / \mathrm{ha}$ e $42 \mathrm{~g} / \mathrm{ha}$ respectivamente, foram observados por Monks et al. (1992). Os herbicidas causaram injúrias nos cultivares, duas semanas após a sua aplicação. As folhas apresentaram clorose, o crescimento foi retardado e ocorreu alongamento da base das folhas. Os herbicidas, entretanto, não afetaram a época de colheita. Os cultivares mostraram-se mais tolerantes ao nicosulfuron que ao primisulfuron.

Pantone \& Baker (1992) estudaram a tolerância de 3 cultivares de arroz ao bromoxynil e ao triclopyr, aplicados em vários estádios de desenvolvimento e duas doses de aplicação. Com exceção dos tratamentos em baixas doses de triclopyr no estádio de 4 para 5 folhas, todos os tratamentos nos estádios de 2 para 3 e 4 para 5 folhas apresentaram visíveis injúrias, como queima das folhas e clorose. $\mathrm{O}$ bromoxynil aplicado nos estádios de 2 para 3 e 4 para 5 folhas na dose mais elevada, ocasionou injúrias em todos os cultivares.

Dottray et al. (1993), verificaram que plantas tolerantes ao Sethoxydim não mostraram sintomas visíveis de injúria nas doses fitotóxicas às gramíneas anuais e em doses 2 e 4 vezes maiores. Essa tolerância foi observada em aplicações seguidas, do estádio vegetativo precoce (3 folhas) até o estádio de desenvolvimento floral (7 folhas). A produção, medida como peso de matéria seca de espigas, não foi reduzida para qualquer dose do herbicida. A altura de plantas, o número de dias para florescimento e a umidade dos grãos na colheita também não foram afetados.

O objetivo desse trabalho é descrever os sinais externos de intoxicação e as alterações histológicas nas folhas de híbridos de milho submetidos à aplicação de nicosulfuron.

\section{MATERIAL E MÉTODOS}

O experimento foi instalado no campo, no delineamento experimental em blocos casualizados, com 3 repetições, sendo utilizados os híbridos de milho AG 106, XL 604, Br 205, Br 206, HT $2 \mathrm{X}$ e CMS 473. As plantas foram submetidas à aplicação de nicosulfuron na dose de 80 g.ha $^{-1}$, com auxílio de pulverizador costal à pressão constante de $\mathrm{CO}_{2}$, provido de barra pulverizadora com 4 bicos tipo "leque" 110.02, com uma vazão de $2401 . \mathrm{ha}^{-1}$. O produto foi aplicado quando as plantas se encontravam com 56 folhas e altura de aproximadamente $25 \mathrm{~cm}$.

Aos 7 dias após a aplicação do produto, foram retiradas amostras de tecido foliar de plantas tratadas, nas regiões que apresentavam sinais externos de intoxicação, e das respectivas testemunhas. Para a observação ao microscópio ótico, pequenas porções de tecido foliar foram colocadas em frascos de vidro contendo solução de FAA (formalina-aceto-álcool : $90 \mathrm{ml}$ de etanol $50 \%, 5 \mathrm{ml}$ de ácido acético glacial e $5 \mathrm{ml}$ de formaldeído a 37\%), segundo a metodologia proposta por Boelcke (1968). Os frascos foram mantidos em dissecador com bomba de vácuo por 4 horas e conservados à temperatura ambiente por 7 dias para completar o processo de fixação. Foram confeccionadas lâminas semipermanentes, cortando-se tranversalmente as amostras de folha com o auxílio de lâmina de barbear. As lâminas foram coradas com safranina a $1 \%$. Foram feitas observações e documentação em fotomicroscópio, marca Docuval.

Para a observação em MEV, utilizou-se a técnica proposta por Santos (1995). As amostras de tecido foliar de plantas tratadas e das testemunhas, foram fixadas em glutaraldeído a 3\% (v/v), em solução tampão de fosfato de potássio a 
$0,05 \mathrm{M}$ e pH 7,4 por 48 horas, a $10^{\circ} \mathrm{C}$. O material foi lavado por seis vezes em solução tampão pura, pós-fixado em tetróxido de ósmio $1 \%$ na mesma solução tampão e mantido em refrigerador por 24 horas. Em seguida, as amostras foram lavadas seis vezes em solução tampão pura e submetidas à desidratação em álcool etílico, na série gradual : 30; 50; 70; 80; 95 e $100 \%$.

As amostras foram submetidas à secagem em secador de ponto crítico e, posteriormente, fixadas sobre suportes apropriados, com fita adesiva de cobre.

As amostras foram recobertas com uma camada de $35 \mathrm{~nm}$ de uma liga de ouro-paládio em "íon-sputter", observadas e elétron-micrografadas em microscópio eletrônico de varredura JEOL JSM 25S II operando em 12,5 kW.

\section{RESULTADOS E DISCUSSÃO}

Aos 7 dias após a aplicação do produto, observou-se, em todos os híbridos testados, clorose e enrugamento das lâminas das folhas centrais em expansão. Observou-se que o sintoma de descoloração das folhas se mostrou mais intenso no período da manhã, diminuindo com o aumento da radiação solar, no decorrer do dia. Tal fato parece indicar uma alteração fisiológica relacionada ao processo fotossintético ou à sintese de clorofilas.

Com a expansão das lâminas foliares, decorridos 14 dias da aplicação do herbicida, verificou-se o deslocamento das manchas cloróticas para a parte central da lâmina foliar. Outro sintoma tardio, surgido aos 14 dias após a aplicação, foi o enrolamento das extremidades das lâminas foliares (Figura 1). Com o decorrer do crescimento das plantas, esses sintomas tenderam a desaparecer, talvez evidenciando uma degradação do produto aplicado, por ação do metabolismo da planta. Damião Filho (1990), observou, em plantas de soja submetidas ao lactofen, alterações morfológicas apenas nos locais onde o produto foi aplicado e uma tendência de recuperação do crescimento das plantas, ao longo do ciclo.

As principais alterações anatômicas observadas nos tecidos foliares restringiram-se às células componentes do sistema dérmico, não se evidenciando alterações celulares no mesofilo.
Pelas análises ao microscópio ótico, observaram-se os seguintes tipos de alterações anatômicas, em todos os híbridos que receberam a aplicação do herbicida:

a) Aumento considerável no número, tamanho e forma das células buliformes em ambas as faces da lâmina foliar, com desaparecimento quase total de células epidérmicas fundamentais (Figuras $2 \mathrm{~A}$ e B).

b) As epidermes ficaram constituídas apenas por células fundamentais com ausência de outros tipos celulares (Figura 2 C).

c) Supressão de células epidérmicas fundamentais ao longo das faces adaxial e abaxial da lâmina foliar e da nervura central, na maioria das vezes, próximo aos feixes vasculares (Figuras $2 \mathrm{D}$ e E).

d) As células buliformes ficaram restritas à face adaxial da lâmina foliar (Figura $2 \mathrm{~F}$ ).

Pela análise das superfícies foliares ao microscópio eletrônico de varredura observou-se que, nas amostras de folhas das plantas que receberam a aplicação do herbicida, ocorreu a perda de simetria bilateral do complexo estomático, em relação às testemunhas (Figura 3 A e B). Essa deformação das células pode ser resultante das alterações no tamanho das células buliformes ou da supressão de células epidérmicas observadas nos cortes tranversais da lâmina foliar.

Na face adaxial da lâmina foliar observou-se também o desaparecimento de células subsidiárias do complexo estomático (Figura $3 \mathrm{C} \mathrm{e}$ D).

Dentro da metodologia empregada, concluiu-se que o sintoma típico de fitotoxidez ocasionada pela aplicação do nicosulfuron na dose de $80 \mathrm{~g} / \mathrm{ha}$, válido para todos os híbridos testados, consiste em descoloração da porção mediana da lâmina das folhas centrais da planta, que se encontravam em fase de expansão no momento da aplicação, sendo este sintoma mais expressivo 7 dias após a aplicação do produto.

As alterações anatômicas foram observadas apenas no sistema dérmico das folhas que tiveram contato direto com o herbicida. 

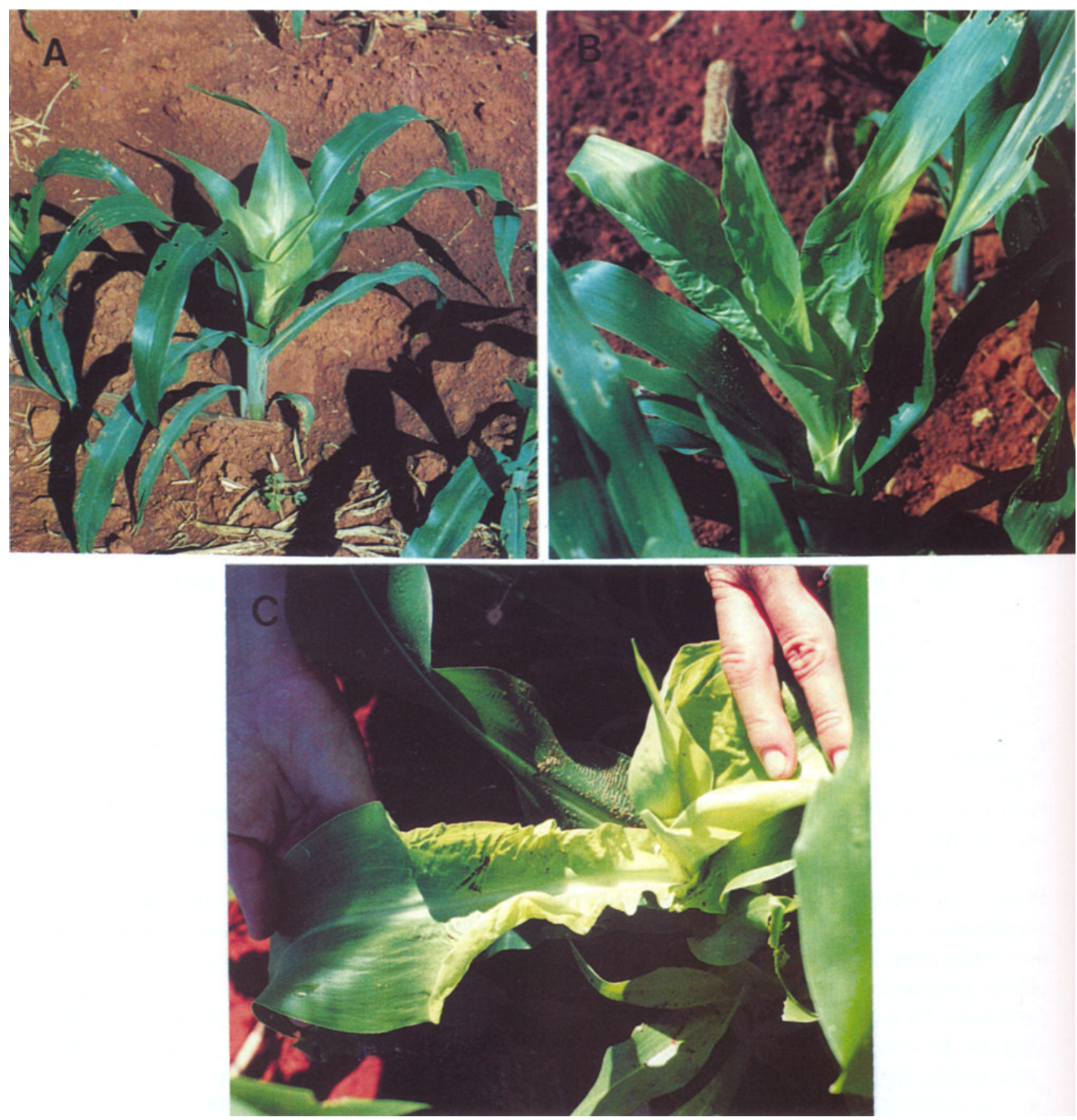

FIGURA 1. Sintomas macroscópicos de fitotoxidade ao nicosulfuron em plantas de milho: A) clorose das folhas centrais da planta, aos 7 dias após a aplicação do produto. B) deslocamento das manchas cloróticas para a região central da lâmina foliar e enrolamento das extremidades das folhas, aos 14 dias após a aplicação do nicosulfuron. C) clorose e enrugamento da lâmina foliar, 7 dias após a aplicação. 

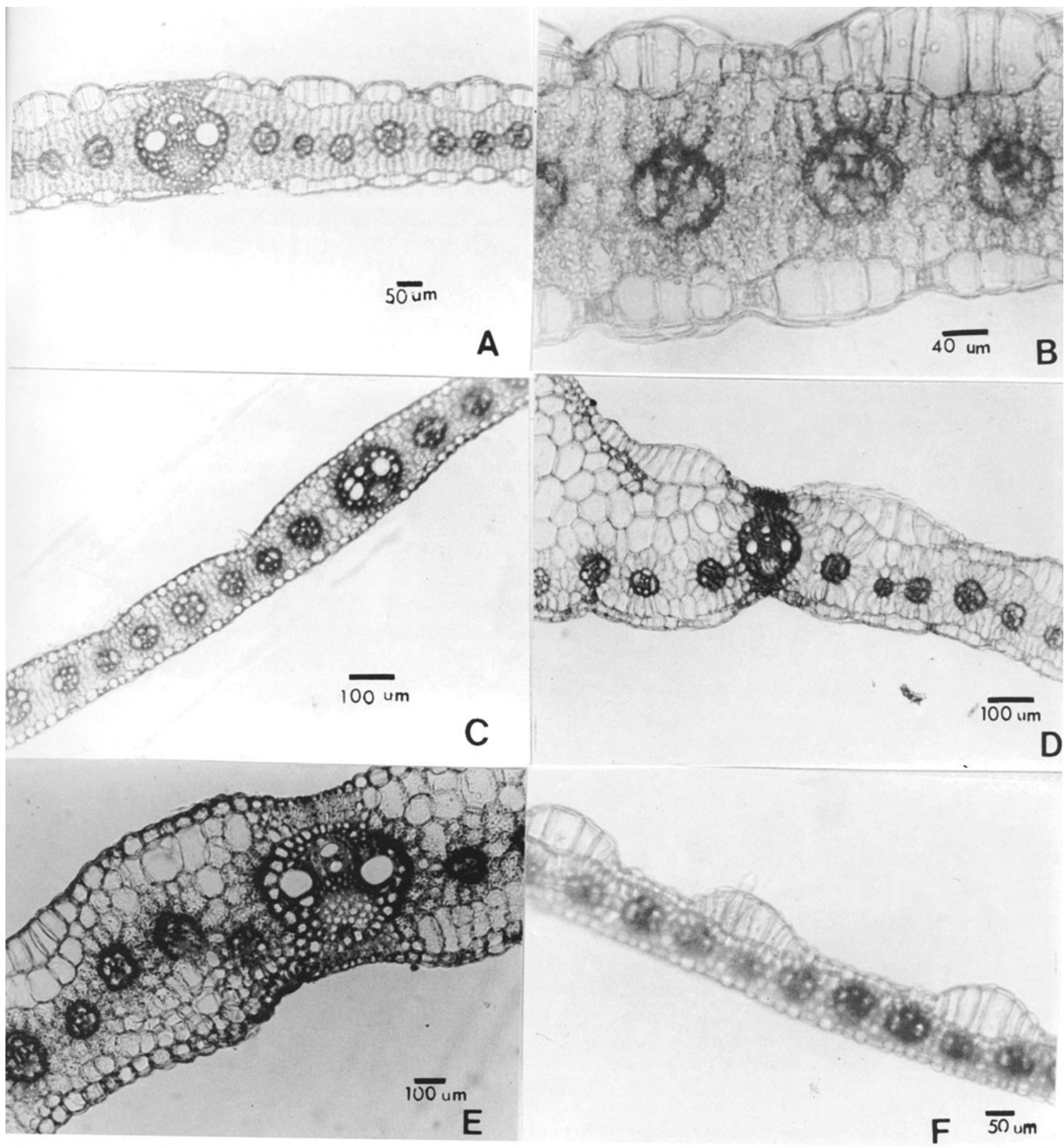

FIGURA 2 A e B. Aumento no número, tamanho e forma das células buliformes em ambas as epidermes. C : Epidermes constituídas apenas por células fundamentais. D e E: Supressão de células epidérmicas próximo aos feixes vasculares. F: Células buliformes restritas à epiderme superior. 


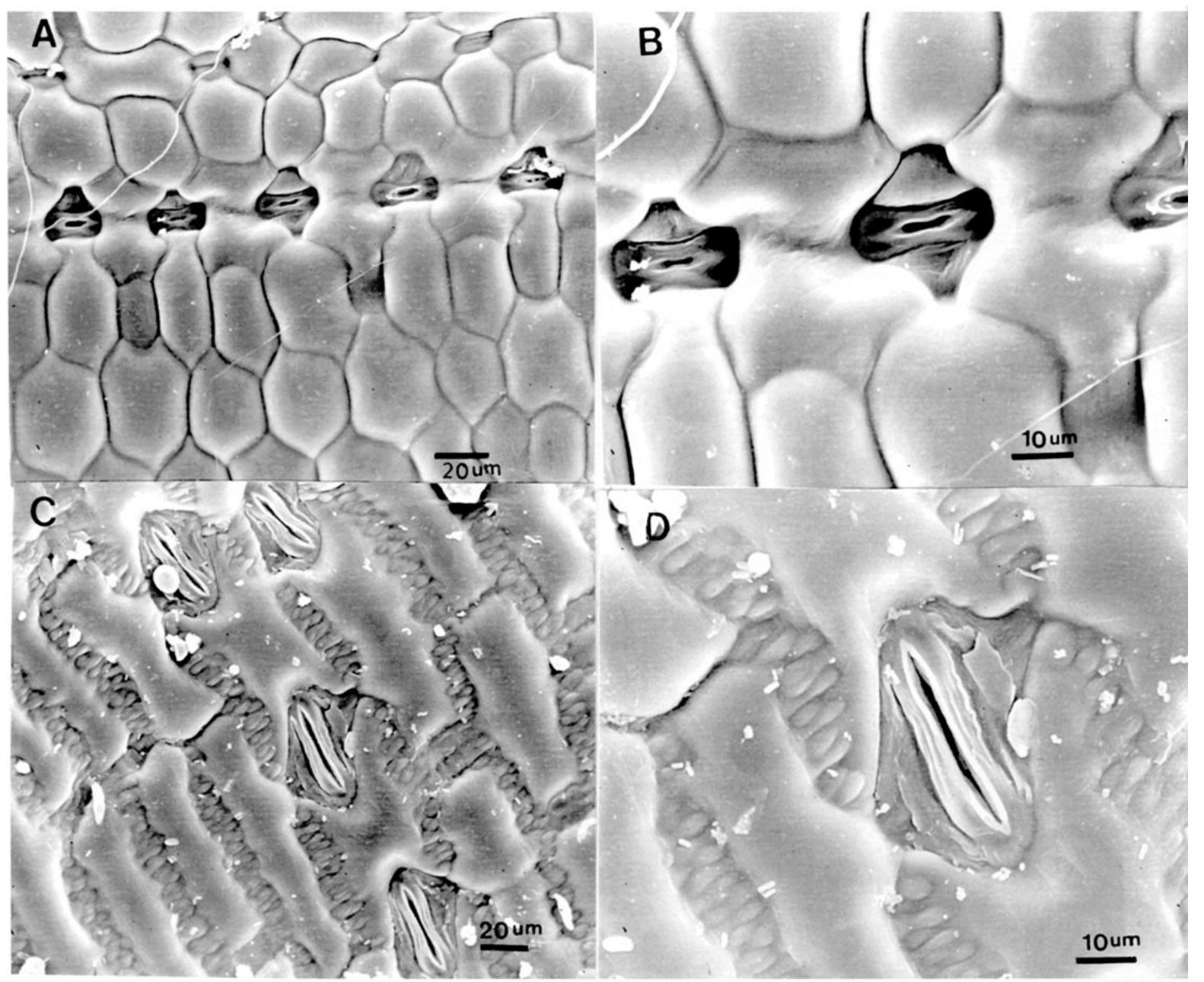

FIGURA 3. A e B. Supressão de células subsidiárias dos estômatos na face adaxial da folha. C e D: Deformação com perda de simetria do complexo estomático, na abaxial da folha. 


\section{LITERATURA CITADA}

ASARE-BOAMAH, N.K.\&FLETCHER, R.A. Physiological and cytological effects of BAS $9052 \mathrm{OH}$ on corn (Zea mays) seedlings. Weed sci., 31: 49-55, 1983.

\section{BOELCKE, O. Guia de Tecnicas en Anatomia}

Vegetal: Catedra de Botanica Agricola. Buenos Aires: Ed. Universidad de Buenos Aires, 1968. 32p.

DAMIÃO FILHO, C.F. Efeitos do herbicida lactofen sobre aspectos biológicos de três cultivares de soja Glycine $\max$ (L.) Merril. Rio Claro: Instituto de Biociências campus de Rio Claro, 1990. 127 p. Tese (Doutor em Ciências Biológicas- Biologia Vegetal).

DOTRAY, P.A., MARSHALL,L.C., PARKER, W.B., WYSE, D.L., SOMERS, D.A., GENGENBACH, B.G. Herbicide tolerance and weed control in Sethoxydim-tolerant corn (Zea mays). Weed sci., 41: 213-217, 1993.

KLEPPE, C.D. \& HARVEY, G. Postemergencedirected herbicides control wild-proso millet (Panicum miliaceum) in sweet corn (Zea mays). Weed technol., 5: 746-752, 1991.

KLEPPE, C.D. \& HARVEY, G. Tolerance of corn (Zea mays) to Sethoxydim applied with precision postemergence-direct sprayer equipament. Weed technol., 3: 663-667, 1989.

MONKS, D.W., MULLINS, C.A. \& JOHNSON, K.E. Response of sweet corn (Zea mays) to nicossulfuron and primisulfuron. Weed technol., 6: 281-283, 1992.

MORTON , C.A. \& HARVEY, R.G. Sweet corn (Zea mays) hybrid tolerance to nicosulfuron. Weed technol., 6: 91-96, 1992.

PANTONE, D.J. \& BAKER, J.B. Varietal tolerance of rice (Oryza sativa) to Bromoxynil and Triclopyr at different growth stages. Weed technol., 6: 968-974, 1992.

SANTOS, J.M. Microscopia Eletrônica de Varredura Aplicada às Ciências Biológicas. Jaboticabal: FUNEP, 1995. 27 p. (Mimeogr.). 